Chugai, Eli Lilly, Grünenthal, Janssen, MSD, Novartis, Pfizer, Roche, and UCB., Consultant for: AbbVie, Chugai, Eli Lilly, Grünenthal, Janssen, MSD, Novartis, Pfizer, Roche, and UCB., Theresa Hunter Employee of: Eli Lilly and Company, Yan Dong Shareholder of: Eli Lilly and Company, Employee of: Eli Lilly and Company, Ann Leung Employee of: Syneos Health, David Sandoval Shareholder of: Eli Lilly and Company, Employee of: Eli Lilly and Company, Luis Leon Shareholder of: Eli Lilly and Company, Employee of: Eli Lilly and Company, Vibeke Strand Consultant for: AbbVie, Amgen, Bayer, BMS, Boehringer Ingelheim, Celgene, Celltrion, CORRONA, Crescendo, EMD Serono, Genentech/Roche, GSK, Horizon, Inmedix, Janssen, Kezar, Lilly, Merck, Novartis, Pfizer, Regeneron, Samsung, Sandoz, Sanofi, Servier, UCB.

DOI: 10.1136/annrheumdis-2019-eular.1612

\section{AB0711 IXEKIZUMAB IMPROVES SIGNS AND SYMPTOMS AND SPINAL INFLAMMATION OF ANKYLOSING SPONDYLITIS/RADIOGRAPHIC AXIAL SPONDYLOARTHRITIS THROUGH ONE YEAR OF TREATMENT IN BIOLOGIC DISEASE MODIFYING ANTI- RHEUMATIC DRUG-NAÏVE PATIENTS}

James Cheng-Chung Wei ${ }^{1}$, Lianne S. Gensler ${ }^{2}$, Jessica A. Walsh ${ }^{3}$, Robert B. M. Landewé ${ }^{4}$, Tetsuya Tomita ${ }^{5}$, Fangyi Zhao ${ }^{6}$, Gaia Gallo ${ }^{6}$, Hilde Carlier $^{6}$, Maxime Dougados ${ }^{7} .{ }^{1}$ Chung Shan Medical University Hospital, Taichung City, Taiwan, Republic of China; ${ }^{2}$ UCSF School of Medicine, San Francisco, United States of America; ${ }^{3}$ University of Utah, Salt Lake City, United States of America; ${ }^{4}$ University of Amsterdam and Atrium Medical Center, Heerlen, Netherlands: ${ }^{5}$ Osaka University Graduate School of Medicine, Osaka, Japan; ${ }^{6}$ Eli Lilly and Company, Indianapolis, United States of America; ${ }^{7}$ Rene Descartes Univ/Cochin Hospital, Paris, France

Background: During 16 weeks (wks) of blinded treatment, ixekizumab (IXE) and an adalimumab (ADA) active reference arm were superior to placebo (PBO) in improving signs and symptoms of radiographic axial spondyloarthritis ( $\mathrm{r}$-axSpA). ${ }^{1}$

Objectives: To assess the safety and efficacy of continuous treatment with IXE through 52 wks in patients (pts) with r-axSpA and to describe clinical response at Wk 52 for pts who switched to IXE following 16 wks of treatment with either ADA or PBO.

Methods: Participants were biologic disease-modifying anti-rheumatic drug (bDMARD)-naïve adult pts with active $\mathrm{r}$-axSpA per Assessment of Spondyloarthritis $(\mathrm{SpA})$ international Society (ASAS) criteria (sacroilliitis centrally defined by modified New York criteria and $>1 \mathrm{SpA}$ feature) and inadequate response or intolerance to non-steroidal anti-inflammatory drugs. Pts were randomized 1:1:1:1 to receive $80 \mathrm{mg}$ IXE every 2 (Q2W) or 4 wks (Q4W), $40 \mathrm{mg}$ adalimumab (ADA) Q2W (active reference arm), or PBO. At Wk 16, pts assigned to IXE continued their assigned treatment and pts receiving PBO or ADA were re-randomized 1:1 to IXE Q2W or IXE Q4W through Wk 52.

Results: Of 164 pts initially randomized to IXE, $146(89 \%)$ completed Wk 52. IXE Q4W and IXE Q2W led to persistent improvements in disease activity, function, objective inflammation (MRI and C-reactive protein), quality of life, health status, and overall functioning for up to 52 wks (Figure and Table). For pts initially assigned to PBO or ADA, ASAS40 response showed a numerical increase upon switching to IXE (Table). Frequencies of treatment-emergent adverse events (AEs) were similar between IXE dosing regimens. Among pts with $\geq 1$ dose of IXE $(N=336)$, serious AEs occurred in $20(6 \%)$ pts. There were no deaths and $11(3 \%)$ pts discontinued due to AEs.

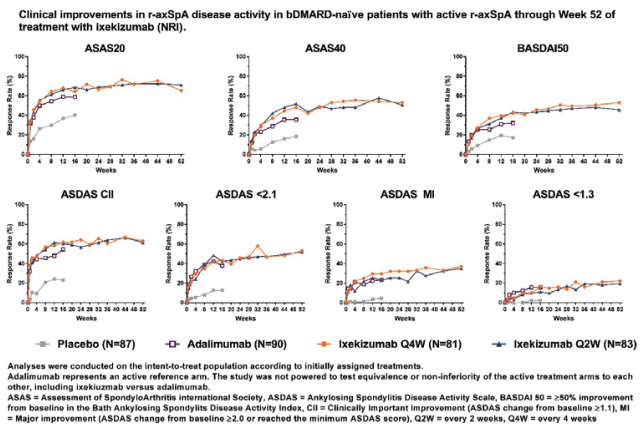

Efficacy of IXE in bDMARD-naïve patients with active r-axSpA

\begin{tabular}{|c|c|c|c|}
\hline $\begin{array}{l}\text { Mean ( } \pm \text { SD) change from baseline, Week } 52 \\
\text { mBOCF (intent-to-treat) }\end{array}$ & \multicolumn{2}{|c|}{$\begin{array}{c}\begin{array}{l}\text { IXE Q4W } \\
(\mathrm{N}=81)\end{array} \\
\end{array}$} & $\begin{array}{c}\text { IXE Q2W } \\
(\mathrm{N}=83)\end{array}$ \\
\hline ASDAS-CRP & \multicolumn{2}{|c|}{$-1.7(1.2)$} & $-1.6(1.0)$ \\
\hline BASDAl $^{\mathrm{a}}$ & \multicolumn{2}{|c|}{$-3.3(2.5)$} & $-3.1(2.3)$ \\
\hline C-Reactive Protein (mg/L) & \multicolumn{2}{|c|}{$-9.2(12.4)$} & $-9.6(14.5)$ \\
\hline BASFI & \multicolumn{2}{|c|}{$-2.8(2.5)$} & $-2.8(2.4)$ \\
\hline SF-36 PCS ${ }^{b}$ & \multicolumn{2}{|c|}{$8.3(9.5)$} & $8.1(7.5)$ \\
\hline ASAS Health Index & \multirow{2}{*}{\multicolumn{2}{|c|}{$-2.7(3.3)$}} & $-3.3(3.6)$ \\
\hline SPARCC Spine Score (observed) ${ }^{c}$ & & & $-8.5(15.9)$ \\
\hline Response (\%) & PBO/All & ADA/All & All IXE/All \\
\hline NRI, extended treatment period population ${ }^{d}$ & $\begin{array}{c}\text { IXE } \\
(\mathrm{N}=86)\end{array}$ & $\begin{array}{c}\text { IXE } \\
(\mathrm{N}=86)\end{array}$ & $\begin{array}{c}\text { IXE } \\
(N=164)\end{array}$ \\
\hline ASAS40 & & & \\
\hline Week 16 & 18.6 & 36.0 & 50.0 \\
\hline Week 52 & 46.5 & 51.2 & 51.8 \\
\hline
\end{tabular}

aBASDAl items were scored on a 0-10 numeric rating scale

${ }^{b}$ SF-36 analyses based on 2009 US norms

'SPARCC Spine: $\mathrm{N}=72$ (IXE Q4W), N=68 (IXE Q2W)

dPatients who received $>1$ dose of IXE during Weeks 16-52

ADA=adalimumab; BASFI=Bath Ankylosing Spondylitis Functional Index; IXE=ixekizumab; mBOCF=modified Baseline Observation Carried Forward; NRI=nonresponder imputation;

PBO=Placebo; Q2W=every 2 weeks; Q4W=every 4 weeks; SF-36 PCS=Medical Outcomes Study 36-Item Short-Form Health Survey Physical Component Summary:

SPARCC $=$ Spondyloarthritis Research Consortium of Canada

Conclusion: Persistent improvements in the signs and symptoms of $r$ axSpA were observed through Wk 52 in pts who received continuous treatment with IXE. ASAS40 response rates at Wk 52 were numerically similar between pts who received continuous treatment with IXE and pts who switched from ADA to IXE. No unexpected safety signals were observed through 52 wks of treatment.

\section{REFERENCES}

[1] van der Heijde, et al. Lancet, 2018

Disclosure of Interests: James Cheng-Chung Wei Grant/research support from: Abbvie, BMS, Celgene, Janssen, Novartis, Pfizer, and UCB pharma, Consultant for: TSH Taiwan, Speakers bureau: Janssen, Novartis, Pfizer and TSH, Lianne S. Gensler Grant/research support from: Abbvie, Amgen, UCB Pharma, Consultant for: Novartis, Lilly, Janssen, Jessica A. Walsh Grant/research support from: Abbvie, Pfizer, Consultant for: Abbvie, Celgene, Lilly, Novartis, Robert B.M. Landewé: None declared, Tetsuya Tomita Consultant for: AbbVie, Astellas, Bristol-Myers Squibb, Eisai, Eli Lilly and Company, Janssen, Mitsubishi Tanabe, Novartis, Takeda, and Pfizer, Speakers bureau: AbbVie, Astellas, Bristol-Myers Squibb, Eisai, Eli Lilly and Company, Janssen, Mitsubishi Tanabe, Novartis, Takeda, and Pfizer, Fangyi Zhao Shareholder of: Eli Lilly and Company, Employee of: Eli Lilly and Company, Gaia Gallo Shareholder of: Eli Lilly and Company, Employee of: Eli Lilly and Company, Hilde Carlier Shareholder of: Eli Lilly and Company, Employee of: Eli Lilly and Company, maxime dougados Grant/research support from: Eli Lilly and Company, Pfizer, AbbVie, and UCB Pharma, Consultant for: Eli Lilly and Company, Pfizer, AbbVie, and UCB Pharma

DOI: 10.1136/annrheumdis-2019-eular.1604

\section{Spondyloarthritis - clinical aspects (other than treatment)}

\section{AB0712 RETINAL AND CHOROIDAL VASCULAR STRUCTURES ARE AFFECTED IN AXIAL SPONDYLOARTHRITIS: AN OPTICAL COHERENCE TOMOGRAPHY STUDY}

Berkay Akmaz ${ }^{1}$, Fahrettin Akay ${ }^{1}$, Dilek Solmaz ${ }^{2}$, Onay Gercik ${ }^{2}$,

Gokhan Kabadayi ${ }^{2}$, Idil Kurut ${ }^{2}$, Servet Akar ${ }^{2} .{ }^{1}$ Izmir Katip Celebi University, Faculty of Medicine, Ophthalmology, Izmir, Turkey; ${ }^{2}$ Izmir Katip Celebi University, Faculty of Medicine, Rheumatology, Izmir, Turkey

Background: Axial spondyloarthritis (axSpA) is a chronic inflammatory dis ease that mainly affects axial skeleton. Ocular inflammation is one of the most common extra-articular manifestations of axSpA, mainly form of acute anterior uveitis (AAU). However posterior segment of the eye was rarely evaluated. The inaccessibility of posterior structures like choroid and retina to direct examination led clinicians to use non-invasive imaging technics. Optical coherence tomography (OCT) is an imaging technology 
providing, high-resolution, and non-invasive cross-sectional view of microscopic, anterior and posterior ocular structures.

Objectives: To evaluate the retina and choroidal vascular structures in axSpA patients by using the advantage of OCT and to compare the changes (if any) with healthy control subjects.

Methods: In total 70 (66\% male; mean age $39.7 \pm 10.4$ years) axSpA patients (50 radiographic- and $20 \mathrm{nr}-\mathrm{axSpA}$ ) and 50 (mean age $41.2 \pm$ 6.2 years) healthy control subjects were included in the analysis. All patients underwent a detailed ophtalmalogic examination by the same opthtalmologist. All individuals with significant refractive errors ( $>3$ diopters of spherical equivalent refraction) and intraocular pressure $\geq 21 \mathrm{mmHg}$ were excluded from the analysis. Choroidal thicknes (ChT), macula, and the ganglion cell complex (GCC) were measured by spectral domain optic coherence tomography (SD-OCT) by the same experienced operator.

Results: Mean ( \pm SD) BASDAI score was $3.6 \pm 2.5$, BASFI score was $3.4 \pm 2.9$, ASDAS-CRP was $2.6 \pm 1.3$ in axSpA patients and $14 \%$ of them has a history of $\mathrm{AAU}$ and $61 \%$ ever treated with TNFi agents There was no significant difference between groups regarding refractive error $(P=0.640)$, intraocular pressure $(P=0.815)$ and $\mathrm{BMI}(P=0.124)$ that could affect the OCT measurements. ChT $(P<0.001)$ were increased and GCC thickness $(P<0.001)$ were decreased in axSpA patients however both layer thicknesses were similar between $r$ - and nr-axSpA patients ( $P=780$ and $P=0.677$ ) (Table). History of uveitis was not associated with ChT and GCC. Although GCC was further decreased in TNFi treated patients (105.8 vs 113.3) this difference did not reach significance $(P=0.058)$. Education level was associated both ChT and GCC measurement. GCC thickness was also releted with $\mathrm{BMI}$ and sex in univarite analysis. Other disease related characteristics including the ones related with disease activity were not related with posterior segment measurements.

Conclusion: Our results showed that beside anterior segment inflammation, posterior segment of the eye could be affected in both $r$ - and nraxSpA patients. Retina and choroidal vascular network forms the posterior segment of the eye. The thinning of GCC which form the inner neural layer of the retina is a good indicative of micro-neurotoxicity in axSpA. Elevation of the ChT may be an important indicator of inflammation.

\begin{tabular}{lccccc}
\multicolumn{7}{l}{ Table. Demographic features and eye assessment results of study population } \\
\hline Variables & $\begin{array}{c}\mathrm{r} \text {-axSpA } \\
(\mathrm{n}=50)\end{array}$ & $\begin{array}{c}\mathrm{nr}-\mathrm{axSpA} \\
(\mathrm{n}=20)\end{array}$ & $\begin{array}{c}\text { AxSpA } \\
(\mathrm{n}=70)\end{array}$ & $\begin{array}{c}\text { Control } \\
(\mathrm{n}=50)\end{array}$ & $\mathrm{P}^{*}$ \\
\hline Age, mean (SD) & 41.3 & $35.8(7.3)$ & 39.7 & $41.2(6.2)$ & $>0.05$ \\
& $(11.1)$ & & $(10.4)$ & & \\
BMI, mean (SD) & $25.1(4.3)$ & $26.3(4.1)$ & $25.5(4.2)$ & $25.9(1.3)$ & $>0.05$ \\
Education years, mean (SD) & $9.1(4.0)$ & $10.6(3.6)$ & $9.5(3.9)$ & $\mathrm{N} / \mathrm{A}$ & - \\
History of AAU, $\mathrm{n}(\%)$ & $6 / 42$ & $2 / 16$ & $8 / 58$ & $\mathrm{~N} / \mathrm{A}$ & - \\
& $(14.3)$ & $(12.5)$ & $(13.7)$ & & \\
TNFi usage, $\mathrm{n}(\%)$ & $32(64)$ & $11(55.0)$ & $43(61.4)$ & $\mathrm{N} / \mathrm{A}$ & - \\
Intraocular pressure, mmHg, & $15.0(2.3)$ & $14.6(1.9)$ & $14.8(2.2)$ & $14.8(2.2)$ & $>0.05$ \\
mean (SD) & & & & & \\
Choroid thickness $\mu \mathrm{M}$, mean & 333.3 & 329.8 & 332.3 & 263.3 & $<0.001$ \\
(SD) & $(68.8)$ & $(69.8)$ & $(68.6)$ & $(26.9)$ & \\
Macula thickness $\mu \mathrm{M}$, mean (SD) & 255.9 & 256.1 & 255.9 & 262.6 & $>0.05$ \\
& $(32.3)$ & $(16.8)$ & $(28.6)$ & $(20.8)$ & \\
GCIPL $\mu \mathrm{M}$, mean (SD) & 106.9 & 113.2 & 108.7 & 112.7 & $<0.001$ \\
& $(8.7)$ & $(27.2)$ & $(16.3)$ & $(7.3)$ & \\
\hline
\end{tabular}

${ }^{*} \mathrm{P}$ between AxSpA and controls.

\section{Acknowledgement: None}

Disclosure of Interests: Berkay Akmaz: None declared, Fahrettin Akay: None declared, Dilek Solmaz: None declared, Onay Gercik: None declared, Gokhan Kabadayi: None declared, Idil Kurut: None declared, Servet Akar Grant/research support from: MSD, Abbvie, Roche, UCB, Novartis, Pfizer, Amgen, Consultant for: MSD, Abbvie, Roche, UCB, Novartis, Pfizer, Amgen, Speakers bureau: Pfizer

DOI: 10.1136/annrheumdis-2019-eular.2420

\section{AB0713 MAGNETIC: RESONANCE IMAGING AND ULTRASONOGRAPHIC MEASUREMENTS OF THE FEMORAL CARTILAGE THICKNESS IN PATIENTS WITH ANKYLOSING SPONDYLITIS}

Fatma Ali, Ayman Darwish, Shereen Refaat, Omnia Adel, Nadia El Ameen. Minia University faculty of medicine, Rheumatology and Rehabilitation, Minia, Egypt

Background: Ankylosing spondylitis (AS) is a progressive inflammatory disease involving cartilaginous structures in the spine and peripheral joints.
Objectives: To examine the role of musculoskeletal ultrasound (MSUS) and magnetic resonance imaging (MRI) in assessing femoral cartilage thicknesses in patients with AS and healthy controls, and to study the correlation between femoral cartilage thicknesses measurements and disease parameters

Methods: Twenty five patients with AS (17 males and 8 females), and twenty five age, sex and BMI matched healthy individuals were included. For all patients assessment of disease activity, spinal mobility, functional limitation and radiological changes were done. Thickness of the femora articular cartilage was measured by MSUS using a 10-18 $\mathrm{MHz}$ linear probe, three mid-point measurements were taken from each knee at the lateral condyle, intercondylar area, and medial condyle. Thickness of the femorotibial articular cartilage was measured by MRI using 1.5 Tesla MR machine.

Results: AS patients had thinner femoral cartilage thickness than the healthy controls at all MSUS measurement sites, with statistically significant differences at medial femoral condyle and intercondylar area in both right and left knees $(p<0.05)$. According to $M R I$ examination, AS patients had statistically significant $(p<0.05)$ thinner cartilage thickness at all subdivisions of femoral and tibial condyles than the healthy controls. Femora cartilage thickness measurements either assessed by MSUS or MRI was negatively correlated with age, age at onset of the disease, and measures of disease activity and radiological changes. Positive correlation between ultrasonographic total femoral cartilage thickness and MRI total femoral cartilage thickness was found $(r=0.49, p=0.02)$.

Conclusion: Patients with ankylosing spondylitis seem to have thinner femoral cartilage thickness than healthy controls. Correlations of knee cartilage thickness (assessed by MSUS and MRI) with demographic data and disease parameters reflect useful value of MSUS and MRI in determining early cartilage loss in AS patients.

\section{REFERENCES}

[1] AIDhaheri F, Almteri T, Dwid N, Majdali A, Janoudi N and Almoallim $\mathbf{H}(2017)$. Rituximab Can Induce Remission in a Patient with Ankylosing Spondylitis Who Failed Anti-TNF- $\alpha$ Agent. Am J Case Rep.; 18 :143-147.

[2] Amin S, LaValley MP, Guermazi A, Grigoryan M, Hunter DJ, Clancy M, et al (2005). The relationship between cartilage loss on magnetic resonance imaging and radiographic progression in men and women with knee osteoarthritis. Arthritis Rheum; 52: 3152-3159.

[3] Andriacchi TP and Favre J (2014). The nature of in vivo mechanical signals that influence cartilage health and progression to knee osteoarthritis. CurrRheumatol Rep.; 16(11) :463.

[4] Anwar F, A-Khayer A, Joseph G, Fraser MH, Jigajinni MV and Allan DB (2011). Delayed presentation and diagnosis of cervical spine injuries in long-standing ankylosing spondylitis.Eur Spine J.; 20(3) :403-7.

Disclosure of Interests: None declared

DOI: 10.1136/annrheumdis-2019-eular.5426

\section{AB0714 BALANCE AND FALLS IN AXIAL SPONDYLOARTHRITIS: A CROSS SECTIONAL STUDY}

Kerilyn Brenda Mewes, Betania Longo, Ana Paula Beckhauser de Campos, Juliana Simioni, Thelma Laroca Skare. Hospital Universitário Evangélico Mackenzie, Department of Rheumatology, Curitiba, Brazil

Background: Spondyloarthritis ( $\mathrm{SpA}$ ) patients may suffer of balance loss predisposing them to falls.

Objectives: To study balance impairment and falls in SpA patients and its association with clinical and epidemiological variables, disease activity, functional and metrology indexes.

Methods: Cross sectional study of $55 \mathrm{SpA}$ patients with axial disease. Clinical and epidemiological were collected from the charts. Balance was accessed by Berg Balance Scale(BBS). The following instruments were applied: ASDAS (Ankylosing Spondylitis Disease Activity Score)-ESR, ASDAS-CRP, BASDAI (Bath Ankylosing Spondylitis Disease Activity Index), BASFI(Bath Ankylosing Spondylitis Functional Index), BASMI(Bath Ankylosing Spondylitis Metrology Index) and ASQoL (Ankylosing spondylitis quality of life questionnaire). The number of falls in the last year was collected.

Results: In this sample, $30.9 \%$ had high risk of falls by the BBS and $25.4 \%$ recalled having at least one fall in the last years. The BBS values were lower in those with white ethnic background $(p=0.01)$; and smok ers $(p=0.03)$ and with $\operatorname{HLA}-B 27(p=0.03)$ and correlated inversely with BASDAl(rho $=-0.28)$, ASDAS-ESR $(\mathrm{rho}=-0.32)$ and ASDAS-CRP $(\mathrm{rho}=-0.33)$, BASFI(rho $=-0.71, \mathrm{p}<0.0001), \mathrm{BASMI}(\mathrm{rho}=-0.80 ; \mathrm{p}<0.0001), \mathrm{ASQ} \mathrm{L}(\mathrm{rho}=-0.57$ $\mathrm{p}<0.001)$ and age $(\mathrm{rho}=-0.50 ; \mathrm{p}<0.001)$. Multivariated analysis showed that BASFI and BASMI were independently associated with $B B S(p=0.02$ and 